\title{
The Architectural Accessibility of Urban Facilities to the Disabled: A Summary of Descriptive Survey Results
}

\author{
L. Zissermann, MA, OTR/L, ${ }^{1}$ J. Tumiel, MA, OTR/L ${ }^{2}$ \\ ${ }^{1}$ Occupational Therapist, Seattle City Public Schools, Seattle, Washington, \\ USA, ${ }^{2}$ Assistant Division Director, Division of Occupational Therapy, College \\ of Arts and Sciences, University of New England, Biddeford, Maine, USA.
}

Key words: Architectural; Accessibility; Handicapped; Physical environment; Adjustments.

This summary reports results of a 1984 descriptive study of the architectural accessibility characteristics of a proportional stratified random sample of facilities serving the physically disabled in the central area of a south eastern industrial city containing a University Medical Center. At the time of the study the city contained approximately 847000 people. The geographical area containing the population and sample of facilities surveyed was a rectangular area located within the central city. The area contained 10.5 square miles and included most of the central business district and the University Medical Center. Two parks and one historical site adjacent to the designated area were also surveyed because of their likelihood of being used by disabled persons.

The survey was designed and conducted by two faculty members and 24 senior University occupational therapy students in co-operation with the city's Mayor's Council for the Betterment of the Handicapped, which advised the Mayor, and the local Independent Living Center, which provided resources for the city's disabled population. Twenty five facility types likely to be used by the disabled were chosen. A listing of all 514 such facilities within the designated geographical area was obtained from the current city telephone directory, a current city map, or a current directory of commercial property. A sample size of 400 was chosen, using tables of random numbers.

The survey instrument used was developed from one used previously by the Independent Living Center. American National Standard Specifications (1980) were used as bases for all accessibility criteria. All surveyors were trained and the instrument was pretested by all surveyors, these being the occupational therapy faculty members and students. The final survey tool contained 146 possible response items allowing assessment of the following facility areas: parking, entrance, general interior, public telephone, public restroom, safety equipment, meeting room, stairs, elevator, water fountain, eating area and/or lounge, 
and hotel or motel room. Also, surveyors asked two questions of the most responsible available person representing the facility:

1. 'Have you had previous exposure to information regarding accessibility?' and

2. 'Do you have any handicapped patrons?'

Surveys were completed on 274 facilities, or $68.5 \%$ of the sample. Percentages of 'accessible' or 'inaccessible' responses were calculated for all survey items across all facilities surveyed. For example, the percentage of all public telephones found to be accessible for all facilities was calculated. Those survey items receiving $75 \%$ or more 'accessible' responses were identified as strengths, and those items receiving $75 \%$ or more 'inaccessible' responses were identified as problem areas in the city.

Results revealed that most entrance doorways, registration desks, corridors, assembly meeting rooms, and eating rooms were accessible. Restroom commodes, faucets, elevators, and restaurant or lounge furniture also generally were usable by the disabled, and most hotel or motel room tubs or showers had at least some accessible parts.

Problem areas included the fact that few facilities had equipment such as braille markings for the visually impaired, flashing lights, volume controls, or special teletypewriter machines for the hearing impaired. Few outside doors were power operated and auxiliary doors, when present, were often not accessible to those in wheelchairs. Most numerous among problem items were restroom barriers to those in wheelchairs. Almost half of the most severe problems involved inaccessible toilets or other inappropriate equipment in public restrooms or hotel/motel restrooms.

Additional observation of the data revealed that $23 \%$ of the facilities surveyed had at least one step to be negotiated before the main entrance was reached, and only 6 of these 64 facilities provided an alternate accessible route for the wheelchair-bound. Only $66 \cdot 7 \%$ of those restaurants with more than one level had all levels accessible to the disabled. Finally, $69 \%$ of the 261 facility representatives responding to the two interview questions reported having received previous information on accessibility, and $78 \%$ reported having served handicapped patrons.

\section{Acknowledgements}

The authors wish to thank Kathleen Kirk, PhD, George Reinhart, PhD, and Mark LaGory, PhD, for their assistance with this study.

This research was supported by a Graduate Faculty Grant from the Graduate School of the University of Alabama in Birmingham, Alabama, USA.

\section{References}

American National Standards Institute, Inc. (1980). American national standard specifications for making buildings and facilities accessible to, and usable by, the physically handicapped. New York.

BAYES K, FrankLIN S, eds 1971 Designing for the handicapped. London: George Godwin Limited.

Duncan J, Gish C, Mulholland MD et al. 1977 Environmental modifications for the visually impaired: a handbook. Visual Impairment and Blindness. 